\title{
Clinical Study of Prevalence, Risk Factors and Causes of Cerebral Palsy
}

\author{
Dr. Abha Samar ${ }^{*}$, Brig Dr. PK Bhatnagar ${ }^{2}$ \\ ${ }^{1}$ Assistant Professor In Obst And Gynae, Pims, Pacific Institute of Medical Sciences, Ambua Road, Village Umarda, Girva, Udaipur Rajasthan, India \\ ${ }^{2}$ Professor in Obst And Gynae, Pims, Pacific Institute of Medical Sciences, Ambua Road, Village Umarda, Girva, Udaipur Rajasthan, India
}

Cerebral palsy is the commonest physical disability in childhood, occurring in 2.0 to 2.5 per 1000 live births [1] Cerebral palsy (CP), a neurodevelopment disorders, is usually associated with abnormalities of pregnancy, particularly 'birth asphyxia' and low birth weight [2]. In the present study all cases were males, mothers were more than 35 years, para4, and uncooked, illiterate and low socio economic status. They all had normal deliveries, were anemic, associated with severe pregnancy induced hypertension, preterm and extremely low birth weight and no genetic overlay Present study $5(0.05 \%)$ cases occurred out of 8500 deliveries. Cranial ultrasound imaging can describe patterns of neonatal brain damage in the low birth weight infant that are highly predictive of later cerebral palsy [3, 4].

Keywords: Cerebral palsy Birth asphyxia Extreme low birth weight Motor defects of new born Congenital brain anomalies.

\footnotetext{
Copyright @ 2020: This is an open-access article distributed under the terms of the Creative Commons Attribution license which permits unrestricted use, distribution, and reproduction in any medium for non-commercial use (NonCommercial, or CC-BY-NC) provided the original author and source are credited.
}

\section{INRODUCTION}

Cerebral Palsy is a group of disorders of movement and posture due to a defect or lesion of the immature brain [5]. Cerebral palsy is a symptom complex, with various types and degrees of motor impairment. These disorders become manifest early in life and are permanent and non-progressive [6]. There has been a consistent rise in the proportion of cerebral palsy associated with preterm and very preterm births. Most cases of cerebral palsy were thought to be caused by asphyxia during either labor or the prenatal period [7]. Prevalence rates of cerebral palsy were used as outcome measures of obstetric practice and neonatal care and it was expected that improvement in these areas would result in lower rates of cerebral palsy [8]. As a result, there was increased use of interventions such as electronic fetal monitoring and caesarean section [9]. Current research suggests that perinatal asphyxia accounts for between $6 \%$ and $8 \%$ of cerebral palsy [10]. Prenatal events are thought to be responsible for approximately $75 \%$ of all cases of cerebral palsy. Cerebral palsy is the commonest physical disability in childhood, occurring in 2.0 to 2.5 per 1000 live births. Known causes of cerebral palsy may be prenatal, perinatal or postnatal. Antenatal causes are congenital brain malformations including malformations of cortical development. Congenital malformations in general are strongly associated with cerebral palsy. Other known antenatal causes of cerebral palsy are vascular events demonstrated by brain imaging (for example, middle cerebral artery occlusion), and maternal infections during the first and second trimesters of pregnancy (rubella, cytomegalovirus, toxoplasmosis). Less common causes of cerebral palsy include metabolic disorders, maternal ingestion of toxins and rare genetic syndromes. Perinatal causes are Problems during labor and delivery and Obstetric emergencies such as obstructed labor, ante partum hemorrhage or cord prolapsed may compromise the fetus causing hypoxia, onset of severe or moderate neonatal encephalopathy in infants of > 34 weeks gestation; and cerebral palsy of the spastic quadriplegic or dyskinetic type [11]. Children with cerebral palsy who have a history of neonatal encephalopathy are more likely to have signs of intrapartum hypoxia such as meconium staining of the amniotic fluid. However, there may be no evidence of perinatal asphyxia in a significant percentage of children with neonatal encephalopathy [12]. Neonatal problems severe hypoglycemia, untreated jaundice and severe neonatal infection may be responsible for cerebral palsy. 
Accidental injuries such as motor vehicle accidents and near-drowning episodes, and non-accidental injuries may result in cerebral palsy. Other causes of postneonatally acquired cerebral palsy include apparent lifethreatening events, cerebrovascular accidents and following surgery for congenital malformations. Meningitis, septicemia and other conditions such as malaria remain extremely important causes of cerebral palsy in developing countries. Multiple pregnancies also have some unique associations. Risk factors may be present before and during pregnancy, during labor and birth, and in the period shortly after birth. Two studies have found that low social class is associated with cerebral palsy in children with normal birth weight. Parity of three or more was a factor in a study of preterm infants [13]. Fetal deaths, maternal intellectual disability, seizures and thyroid disease may be associated. Pre-eclampsia is associated with an increased risk of cerebral palsy in term infants, but this association does not seem to exist in preterm infants [14]. The frequency of cerebral palsy decreased with increasing gestational age and birth weight. Antenatal complications occurred in women with preterm deliveries. Factors associated with an increased risk of cerebral palsy after adjustment for gestational age were chorioamnionitis prolonged rupture of membranes and maternal infection. Pre-eclampsia was associated with a reduced risk of cerebral palsy as was delivery without labor. There was no increased risk of cerebral palsy with intrauterine growth retardation

\section{MATERIAL AND METHODS}

The present study has been undertaken to determine the maternal and fetal causative factors in development of cerebral palsy and to suggest preventive measures. Study has been carried out at pacific institute of medical sciences umarda udaipur rajasthan. Period of study has been 2014 to 2019. This is retrospective study and the old records were reviewed by the author for fetal weight at birth and sex of neonate. Single and twin live births were included. Stillbirth, intrauterine deaths and congenital defects were excluded. Maternal age, parity, education, socio-economic status, period of gestation and type of delivery were included. Preexisting maternal disease, anemia, hypertension, heart disease and liver disease were recorded. Maternal weight at first visit, maternal height, total ante natal visits, obstetric complications, drug and medication use, tobacco use were recorded. Maternal symptoms, swelling feet, weakness, headache, bleeding or discharge per vagina were recorded. Physical findings, anemia, swelling feet and body, BP more than 130/90 $\mathrm{mm}$ of hg, twins mal presentations were recorded. Laboratory studies, hemoglobin, leukocyte count, blood sugar, urea, keratinize; liver enzymes, urine albumin and sugar were recorded. Imaging studies, gestational age, ultrasonography, Placental localization, cervical length, twins, congenital defects, presentation and positions were noted. Fluid balance, tocolytic use and type, evidence of pre-eclampsia, infection, premature rupture of membranes, pre term labor and therapeutic measures ,type of delivery normal or caesarean section were also recorded. Pregnancy outcomes included gestational age at delivery, birth weight, mode of delivery, and Agar scores were recorded.

\section{OBSERVATION}

Table-1: Maternal Age distribution of cerebral palsy neonates

\begin{tabular}{|l|l|l|l|}
\hline S.no & Age in years & No of patients & percentage \\
\hline 1 & Less than 20 & nil & nil \\
\hline 2 & $20-25$ & nil & nil \\
\hline 3 & $26-30$ & nil & nil \\
\hline 4 & $31-35$ & 04 & 80 \\
\hline 5 & 36 and more & 1 & 20 \\
\hline & & 05 & 100 \\
\hline
\end{tabular}

Result-Max 04 cases (80. \%) belonged to 31 -35 years and 1 (20\%) was more than 36 years

Table-2: Maternal Parity distribution of cases of cerebral palsy neonates

\begin{tabular}{|l|l|l|l|}
\hline S. No. & Parity & Number & Percentage \\
\hline 1 & 0 & nil & nil \\
\hline 2 & 1 & nil & nil \\
\hline 3 & 2 & nil & nil \\
\hline 4 & 3 & nil & Nil \\
\hline 5 & 4 & 4 & 80 \\
\hline 6 & 5 & 1 & 10 \\
\hline & & 5 & 100 \\
\hline
\end{tabular}

Results 4(80\%) were Para 4, and 1 (20\%) cases were Para 5. 
Abha Samar \& PK Bhatnagar; Sch Int J Obstet Gynec, Feb. 2020; 3(2): 56-61

Table-3: Maternal ante natal care education socio economic status distribution of CEREBRAL PALSY BABY

\begin{tabular}{|l|l|l|l|}
\hline S.no & Maternal antenatal visits & No of patients & percentage \\
\hline 1 & nil & 4 & 80 \\
\hline 2 & $1-2$ & 1 & 20 \\
\hline 3 & 3 and more & nil & nil \\
\hline & Maternal education & & \\
\hline 4 & Less than class 5 & 4 & 80 \\
\hline 5 & Class 5 to class 10 & 1 & 20 \\
\hline 6 & More than class 10 & & \\
\hline & Socio economic class & & \\
\hline 7 & Very low & 04 & 80 \\
\hline 8 & low & 01 & 20 \\
\hline 9 & middle & & \\
\hline 10 & high & & \\
\hline
\end{tabular}

Result - max 4(80\%) were totally unbooked without single antenatal visit, $1(20 \%)$ had $1-2$ visits a $4(80 \%)$ were illiterate $1(20 \%)$ were less than 10 standard $4(80 \%)$ were very low socio economic status, $1(20 \%)$ were of low socio economic status.

Table-4: Maternal risk factors of CEREBRAL PALSY BABY

\begin{tabular}{|l|l|l|l|}
\hline S. No. & Maternal risk factors & number & percentage \\
\hline 1 & Mode of delivery & & \\
\hline & Normal vaginal delivery & 5 & 100 \\
\hline 2 & Caesarean delivery & nil & \\
\hline & Anemia & & \\
\hline & 10 gm\% and more & nil & \\
\hline & Mild 8-10 gm\% & nil & \\
\hline & Moderate 6- 8 gm\% & nil & \\
\hline 3 & Severe less than 6gm\% & 5 & 100 \\
\hline & Pregnancy induced hypertension & & \\
\hline & Mild 130/90 and above & & \\
\hline & Moderate 150/100 and above & & \\
\hline & Severe 170/110 and above & 4 & 80 \\
\hline 5 & Eclampsia & 1 & 20 \\
\hline 6 & Abruptio placentae & 1 & 20 \\
\hline 7 & Pre term rupture of membranes & 5 & 100 \\
\hline $\begin{array}{l}\text { Weight of neonate } \\
\text { Less than 1000 gm } \\
1000-1500 \text { gm } \\
\text { Less than 2500gm }\end{array}$ & 5 & 100 \\
\hline
\end{tabular}

All 5(100\%) had normal delivery and had severe anemia .5 (100\%) had severe degree of pregnancy induced hypertension. 1(20\%) had eclampsia. $1(20 \%)$ had ante partum hemorrhage. 5 $(100 \%)$ had pre mature rupture of membranes and preterm delivery. $5(100 \%)$ neonates were extremely low birth weight (less than 1000gm)

\section{RESULTS}

04 cases $(80 . \%)$ belonged to $31-35$ years and $1(20 \%)$ was more than 36 years $4(80 \%)$ were Para 4 , and $1(20 \%)$ cases were Para 5. $\max 4(80 \%)$ were totally uncooked without single antenatal visit,1(20\%) had 1-2 visits Maximum $4(80 \%)$ were illiterate 1 (20\%) were less than 10 standard Most ladies 4(80\%) were very low socio economic status, $1(20 \%)$ were of low socio economic status $5(100 \%)$ were normal delivery. $5(100 \%)$ were severely anemic $.5(100 \%)$ had severe degree of pregnancy induced hypertension.1 (20\%) had eclampsia. $1(20 \%)$ had ante partum hemorrhage. $5(100 \%)$ had pre mature rupture of membranes and preterm delivery. 5(100\%) neonates were extremely low birth weight (less than $1000 \mathrm{gm}$ ).

\section{DISCUSSION}

In the present study prevalence rate has been low 5(00.05 per 1000 live births) as compared to reported incidence All cases were males mothers more than 35 years, para4 and more unbooked illiterate low socio economic status normal deliveries anemic associated with severe pregnancy induced hypertension preterm extremely low birth weight no genetic overlay The increase in survival of very preterm babies was accompanied by a sharp increase in the rate of cerebral 
palsy in this group. The relation between antenatal and intrapartum factors and cerebral palsy in such babies has not been well defined [15].

It is likely that at least a proportion of the $\mathrm{CP}$ cases will be explained by more complex genetics and not just single major gene effect [16]. Established environmental risk factors for $\mathrm{CP}$, such as IUGR, infection, and prematurity, may interact with predisposing genetic variants and potentiate and multiply the chance of a $\mathrm{CP}$ outcome $\mathrm{CP}$ rates have remained the same despite major advances in obstetrics and neonatology including a 6-fold increase in cesarean delivery rates and liberal induction policies to reduce post maturity[17]. The long-term goal is the prevention of CP. Targeted screening of parents for inherited causative genes, embryo preimplantation screening, or antenatal diagnostic DNA techniques in early pregnancy are possibilities in the near future. Gene silencing and gene therapy remain a more distant and exciting prospect in the prevention of some of the CPs [18]. Premature delivery is the single most important antecedent of cerebral palsy, and the increase in survival of very small infants resulting from newborn intensive care may augment this contribution in the future. Cranial ultrasound imaging can describe patterns of neonatal brain damage in the low birthweight infant that are highly predictive of later cerebral palsy.

Future research on the causes of cerebral palsy may benefit from improvements in the neurological assessment of the fetus prior to labor and from a clearer understanding of the role of endocrine factors, particularly thyroid disorders, in neurologic development [19].

The rate of cerebral palsy was increased in children whose mothers received thyroid hormone or oestrogen in pregnancy [20]. Ante partum hemorrhage is associated with mortality, cerebral palsy and white matter damage in preterm infants but if cases are compared with controls born at the same gestation, ante partum hemorrhage is found to increase the risk of cerebral palsy associated with preterm birth, but not to add any further risk [21]. Two mutations have been identified that predispose heterozygous carriers to venous thrombosis. One is a mutation localized to the Factor V gene (Factor V Leiden mutation, VL) and is the most common cause of familial thrombosis. The second is the gene for prothrombin. The carrier frequency in Caucasian men is $5.5 \%$ and in Caucasian women is $4.8 \%$. A report of three babies with hemiplegic cerebral palsy who were heterozygous for the Factor V Leiden mutation [22] has prompted current research in this area. In the three cases reported, there was a suggestion that placental thrombosis, or neonatal stroke, may have occurred and resulted in hemiplegic. There appears to be an association between inflammatory mediators and markers of autoimmune and coagulation disorders with cerebral palsy [23]. Multiple pregnancies the increased risk of both mortality and cerebral palsy in multiple births has been known for many years. Multiple pregnancies are associated with preterm delivery, poor intrauterine growth, birth defects and intrapartum complications. However the increased risk to twins of cerebral palsy is not entirely explained by their increased risk of prematurity and low birth weight [24]. In monochorionic twin pregnancies, death of one twin is recognized as being an important risk factor for the surviving co-twin having cerebral palsy. The death of one twin may impair the neurological development of the survivor throughout gestation [25]. Meta-analysis of four studies has demonstrated that the antenatal death of a co-twin is associated with a six-fold increase in rate of cerebral palsy per twin confinement, or an 11-fold increase in rate per child [26]. The live-born co-twin of a fetus that died in utero is at increased risk of cerebral impairment, the overall risk being 20\% [27]. Risk factors during labor Major events likely to cause perinatal asphyxia include prolapsed cord, massive intrapartum hemorrhage, prolonged or traumatic delivery due to cephalopelvic disproportion or abnormal presentation, a large baby with shoulder dystocia and maternal shock from a variety of causes [28]. Other reported associations with cerebral palsy include prolonged second stage of labour, emergency caesarean section, premature separation of the placenta and abnormal foetal position [29]. In considering these factors, it is important to remember that it may not be the event itself that is the causal factor, but rather that the event is simply associated with one or more true causal factors. Substantial evidence has recently emerged that intrauterine exposure to infection, particularly chorioamnionitis, in the latter stages of pregnancy and during labour, is a strong risk factor for cerebral palsy, particularly in term infants [30]. Furthermore, infants of normal birth weight born to infected women were more often hypertensive, needed intubation, had neonatal seizures and a clinical diagnosis of hypoxic-ischemic encephalopathy [31]. In a met analysis of studies that addressed the association between clinical and histological chorioamnionitis and cerebral palsy or periventricular leukomalacia in both preterm and full term infants [32], chorioamnionitis was found to be a risk factor for both cerebral palsy and periventricular leucomalacia. More information is needed about the role of infection in the perinatal period and this is an area of active research. Other associations with cerebral palsy include prolonged rupture of the membranes in infants of all gestations [33].

\section{CONCLUSION}

Cerebral palsy (CP), unlike many other neurodevelopmental disorders, is associated with abnormalities of pregnancy and birth, particularly 'birth asphyxia' and low birthweight Premature delivery is the single most important antecedent of cerebral palsy, and the increase in survival of very small infants 
resulting from newborn intensive care may augment this contribution in the future. Cranial ultrasound imaging can describe patterns of neonatal brain damage in the low birthweight infant that are highly predictive of later cerebral palsy.

\section{REFERENCES}

1. Williams, K., Hennessy, E., \& Alberman, E. (1996). Cerebral palsy: effects of twinning, birthweight, and gestational age. Archives of Disease in Childhood-Fetal and Neonatal Edition, 75(3), F178-F182.

2. Wu, Y. W., \& Colford Jr, J. M. (2000). Chorioamnionitis as a risk factor for cerebral palsy: a meta-analysis. Jama, 284(11), 1417-1424.

3. MacLennan, A. (1999). A template for defining a causal relation between acute intrapartum events and cerebral palsy: international consensus statement. Bmj, 319(7216), 1054-1059.

4. Hankins, G. D., \& Speer, M. (2003). Defining the pathogenesis and pathophysiology of neonatal encephalopathy and cerebral palsy. Obstetrics \& Gynecology, 102(3), 628-636.

5. Van de Riet, J. E., Vandenbussche, F. P., Le Cessie, S., \& Keirse, M. J. (1999). Newborn assessment and long-term adverse outcome: a systematic review. American journal of obstetrics and gynecology, 180(4), 1024-1029.

6. Walstab, J., Bell, R., Reddihough, D., Brennecke, S., Bessell, C., \& Beischer, N. (2002). Antenatal and intrapartum antecedents of cerebral palsy - a case-control study. Australian and New Zealand Journal of Obstetrics and Gynaecology, 42: 138146.

7. Topp, M., Langhoff-Roos, J., \& Uldall, P. (1997). Preterm birth and cerebral palsy. Predictive value of pregnancy complications, mode of delivery, and Apgar scores. Acta Obstetrica and Gynecologica Scandinavica, 76: 843-848.

8. Nelson, K.B., J.H. (1985). Ellenberg Antecedents of cerebral palsy, I: univariate analysis of risks $A m$ J Dis Child, 139, 1031-1038

9. Nelson, K.B., J.H. (1986). Ellenberg Antecedents of cerebral palsy: multivariate analysis of risk $N$ Engl J Med, 315 81-86

10. Blair, E.F. (1988). StanleyIntrapartum asphyxia: a rare cause of cerebral pals. J Pediatr, 112, 515-519

11. Strijbis, E.M., I. Oudman, P. van Essen, A.H. (2006). MacLennanCerebral palsy and the application of the international criteria for acute intrapartum hypoxia, Obstet Gynecol, 107, 13571365

12. Badawi, N.K., Kurinczuk, J.J., Keogh, J.M. (1988). Intrapartum risk factors for newborn encephalopathy: the Western Australian casecontrol study BMJ, 317, 1554-1558

13. Badawi, N., Felix, J. F., Kurinczuk, J. J., Dixon, G., Watson, L., Keogh, J. M., ... \& Stanley, F. J. (2005). Cerebral palsy following term newborn encephalopathy: a population-based study. Developmental medicine and child neurology, 47(5), 293-298.

14. Moreno-De-Luca, A., Ledbetter, D. H., \& Martin, C. L. (2012). Genetic insights into the causes and classification of the cerebral palsies. The lancet neurology, 11(3), 283-292.

15. McMichael, G., Bainbridge, M. N., Haan, E., Corbett, M., Gardner, A., Thompson, S., ... \& O'callaghan, M. E. (2015). Whole-exome sequencing points to considerable genetic heterogeneity of cerebral palsy. Molecular psychiatry, 20(2), 176-182.

16. Wong, L., \& Maclennan, A. H. (2011). Gathering the evidence: cord gases and placental histology for births with low Apgar scores. Australian and New Zealand Journal of Obstetrics and Gynaecology, 51(1), 17-21.

17. Martin, J. N., Palmer, S. M., Martin, R. W., Lucas, J. A., Meeks, G. R., Bucovaz, E. T., \& Morrison, J. C. (1986). Correlation of neonatal acid-base status with Apgar scores and fetal heart rate tracings. American Journal of Obstetrics \& Gynecology, 154(6), 1306-1311.

18. Phelan, J. P., Korst, L. M., \& Martin, G. I. (2011). Application of criteria developed by the Task Force on Neonatal Encephalopathy and Cerebral Palsy to acutely asphyxiated neonates. Obstetrics \& Gynecology, 118(4), 824-830.

19. Sartwelle, T. P., \& Johnston, J. C. (2015). Cerebral palsy litigation: change course or abandon ship. Journal of child neurology, 30(7), 828-841.

20. Murphy, D. J., Johnson, A. M., Sellers, S., \& MacKenzie, I. Z. (1995). Case-control study of antenatal and intrapartum risk factors for cerebral palsy in very preterm singleton babies. The Lancet, 346(8988), 1449-1454.

21. Oskoui, M., Coutinho, F., Dykeman, J., Jette, N., \& Pringsheim, T. (2013). An update on the prevalence of cerebral palsy: a systematic review and meta-analysis. Developmental Medicine \& Child Neurology, 55(6), 509-519.

22. Garne, E., Dolk, H., Krägeloh-Mann, I., Ravn, S. H., Cans, C., \& Group, S. C. (2008). Cerebral palsy and congenital malformations. European Journal of Paediatric Neurology, 12(2), 82-88.

23. Blair, E., Al Asedy, F., Badawi, N., \& Bower, C. (2007). Is cerebral palsy associated with birth defects other than cerebral defects?. Developmental Medicine \& Child Neurology, 49(4), 252-258.

24. McIntyre, S., Blair, E., Badawi, N., Keogh, J., \& Nelson, K. B. (2013). Antecedents of cerebral palsy and perinatal death in term and late preterm singletons. Obstetrics \& Gynecology, 122(4), 869877.

25. Grether, J.K., K.B. (1997). NelsonMaternal infection and cerebral palsy in infants of normal birth weight JAMA, 278, 207-211

26. O'Callaghan, M. E., MacLennan, A. H., Gibson, C. S., McMichael, G. L., Haan, E. A., Broadbent, J. L., ... \& Dekker, G. A. (2011). Epidemiologic 
associations with cerebral palsy. Obstetrics \& Gynecology, 118(3), 576-582.

27. Nelson, K. B., \& Grether, J. K. (1998). Potentially asphyxiating conditions and spastic cerebral palsy in infants of normal birth weight. American journal of obstetrics and gynecology, 179(2), 507-513.

28. Nelson, K. B., \& Leviton, A. (1991). How much of neonatal encephalopathy is due to birth asphyxia?. American journal of diseases of children, 145(11), 1325-1331.

29. Wu, Y. W., Escobar, G. J., Grether, J. K., Croen, L. A., Greene, J. D., \& Newman, T. B. (2003). Chorioamnionitis and cerebral palsy in term and near-term infants. Jama, 290(20), 2677-2684.

30. Yoon, B. H., Romero, R., Park, J. S., Kim, C. J., Kim, S. H., Choi, J. H., \& Han, T. R. (2000). Fetal exposure to an intra-amniotic inflammation and the development of cerebral palsy at the age of three years. American journal of obstetrics and gynecology, 182(3), 675-681.
31. Bashiri, A., Burstein, E., \& Mazor, M. (2006). Cerebral palsy and fetal inflammatory response syndrome: a review. Journal of perinatal medicine, 34(1), 5-12.

32. Gibson, C. S., MacLennan, A. H., Hague, W. M., Haan, E. A., Priest, K., Chan, A., ... \& South Australian Cerebral Palsy Research Group. (2005). Associations between inherited thrombophilias, gestational age, and cerebral palsy. American journal of obstetrics and gynecology, 193(4), 1437e1.

33. Gibson, C. S., MacLennan, A. H., Goldwater, P. N., Haan, E. A., Priest, K., Dekker, G. A., \& South Australian Cerebral Palsy Research Group. (2006). The association between inherited cytokine polymorphisms and cerebral palsy. American journal of obstetrics and gynecology, 194(3), 674e1. 